\title{
Durability and Compatibility of Lime-Based Mortars: the Effect of Aggregates
}

\author{
Ana Rita Santos ${ }^{1, *}$, Maria do Rosário Veiga ${ }^{1}$, Luís Matias ${ }^{1}$, António Santos Silva ${ }^{2}$ and Jorge de \\ Brito $^{3}$

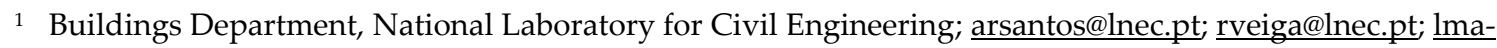 \\ tias@lnec.pt \\ 2 Materials Department, National Laboratory for Civil Engineering; ssilva@lnec.pt \\ 3 Department of Civil Engineering, Architecture and Georresources, Instituto Superior Técnico, Univer- \\ sidade de Lisboa; jb@civil.ist.utl.pt \\ * Correspondence: arsantos@lnec.pt; Tel.: +351-218-443-989
}

\begin{abstract}
In order to fully perform their functions and be durable, mortars for renders and plasters are requested to have a set of characteristics that can vary with the type of exposure to external environmental actions and the type of substrate. Generally, they need moderate strength, high deformability, some water protection capability, good adhesion to the substrate, and compatibility with the pre-existent materials.

The presence of water and its movement inside the pore structure of the mortars are among the most significant causes of degradation. Moreover, several authors consider that the main factors for durability and good performance of lime-based mortars are mostly related with the good quality of the binder and the use of adequate aggregates.

This paper intends to study the effect of ageing on the properties and durability of air lime mortars, using aggregates of different mineralogy. For this purpose, different mortars compositions are exposed to an accelerated weathering test under defined conditions. The obtained characteristics are discussed and compared with the results obtained with the same mortars tested in laboratory conditions. The effects of the aggregate type on the durability of mortars seem to be linked to their effects on the mortars porous structure.
\end{abstract}

Keywords: mortar; aerial lime; aggregates; experimental testing; performance

\section{Introduction}

Whenever possible, conservation strategies are always the best option to consider when degradation affects ancient renders. Nevertheless, if defects are severe, it may be necessary to substitute old renders partially or completely. In those cases, it is essential to choose mortars presenting good compatibility with the substrate and enough durability concerning the environment.

Mortars for use as renders and plasters have important functions in the aesthetics and protection of the masonry, and a relevant overall contribution to the physical behaviour of the wall. They need to have the ability to protect the wall against rain, avoiding quick penetration in high quantity; they are also required to ease the exit of water as much as possible, in liquid and vapour form, both infiltrated and originated by capillary rising [1]. In fact, the presence of water and its movement inside the pore structure of the mortars are among the most significant causes of degradation [2-4].

Additionally, several authors consider that the main factors for durability and good performance of lime-based mortars are mostly related with the good quality of the binder and the use of adequate aggregates with appropriate particle size distribution. The binder defines, to a certain point, the ki- 
netics of the strength increase, the balance between deformability and strength and the chemical characteristics of the mortars; however, different aggregates can significantly change the final physical and mechanical properties [1].

In order to study the influence of the aggregates nature on the mortar durability, an experimental program was carried out on lime mortars applied on panels of a large scale model and further subjected to an artificial ageing test developed considering extreme environmental conditions (rain, heat and freeze/thaw) that occur in Portugal. Accelerated weathering tests are the easiest, quickest, and most commonly used way of studying the durability of a construction material exposed to given environmental conditions.

The same mortars were also cured under laboratory conditions to check the compatibility of the solutions and their performance in aggressive conditions.

This work allows evaluating and comparing the durability of the repair lime mortars prepared with three different aggregates.

\section{Experimental work}

\subsection{Mortars}

A calcium hydrated lime powder (CL90-S), according to the European standard EN 459-1 [5], and three kinds of aggregates have been used to prepare three mortar types, with a 1:3 (binder: aggregate) volumetric ratio.

In this work the sands used are: siliceous sand (RT) $\left(1490 \mathrm{~kg} / \mathrm{m}^{3}\right)$, crushed limestone sand (C) $\left(1400 \mathrm{~kg} / \mathrm{m}^{3}\right)$ and crushed granite sand $(\mathrm{G})\left(1520 \mathrm{~kg} / \mathrm{m}^{3}\right)$. The grain size distribution of the aggregates is presented in Figure 1.

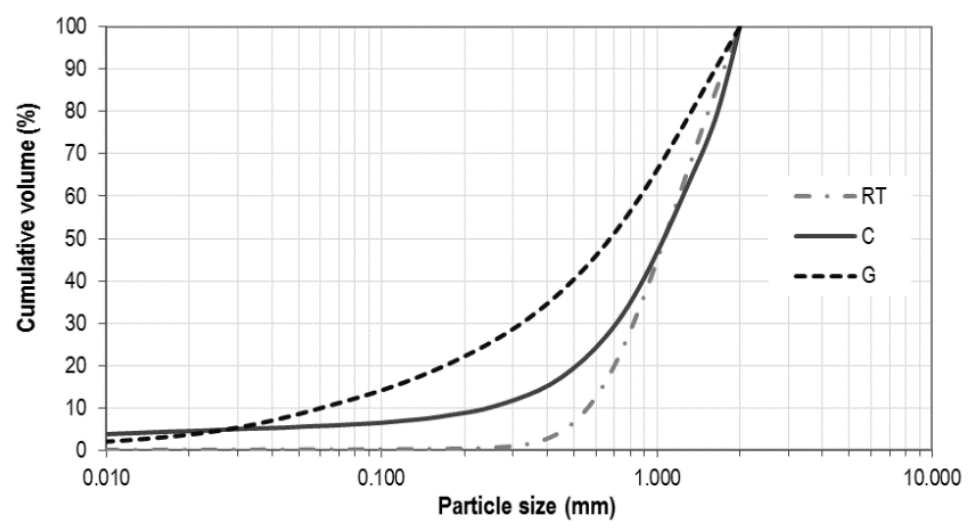

Figure 1. Grain size distribution of the aggregates.

Water was added to achieve a $150 \pm 5 \mathrm{~mm}$ initial flow diameter for all mortars, measured by the flow table test, according to EN 1015-3 [6], adjusting the water/binder ratio (w/b) to obtain this flow, which was found to ensure good workability for these lime mortars (Table 1).

Table 1. Mortars compositions.

\begin{tabular}{ccccc}
\hline \multirow{2}{*}{ Acronym's } & \multicolumn{2}{c}{ Composition } & $\begin{array}{c}\text { Volume propor- } \\
\text { tion (b/a) }\end{array}$ & w/b ratio \\
\cline { 2 - 3 } & Binder & Aggregate & & 2.8 \\
Ca RT & & siliceous sand & & 2.6 \\
Ca C & \multirow{2}{*}{ CL90-S } & crushed limestone sand & $1: 3$ & 2.7 \\
Ca G & & crushed granite sand & & 2 \\
\hline
\end{tabular}

Mortars were applied on an irregular masonry wall, made of limestone, air lime and silica sand, in two layers of $10 \mathrm{~mm}$ each (Figure 2). The second layer, with the same composition of the first, was applied 15 days after the application of the first layer. After the application, all the panels showed good appearance, without cracks or disaggregation. 
Mortars were also cast in $40 \times 40 \times 160 \mathrm{~mm}^{3}$ moulds and stored and cured under controlled conditions of temperature and relative humidity of $20 \pm 2{ }^{\circ} \mathrm{C}$ and $65 \% \mathrm{RH}$ until testing.

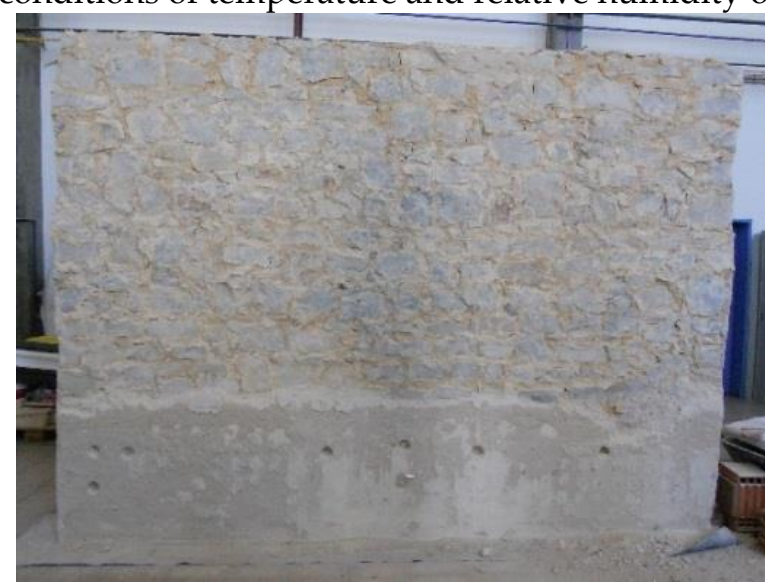

(a)

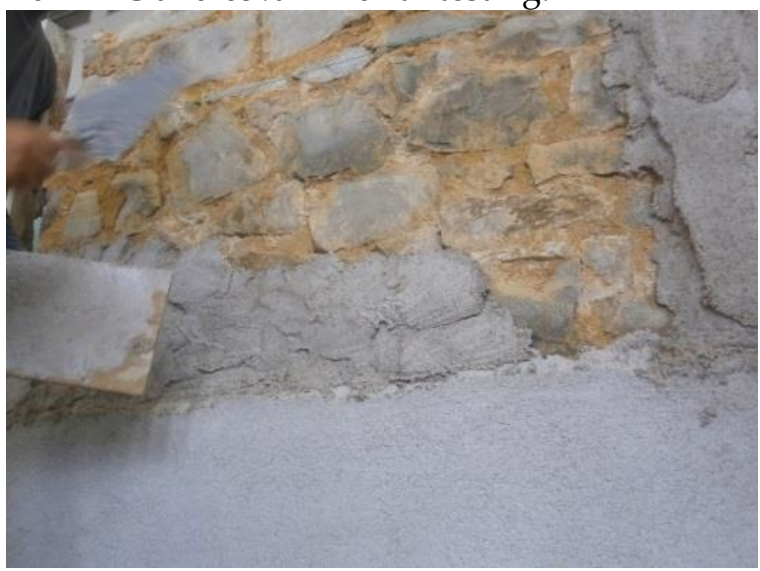

(b)

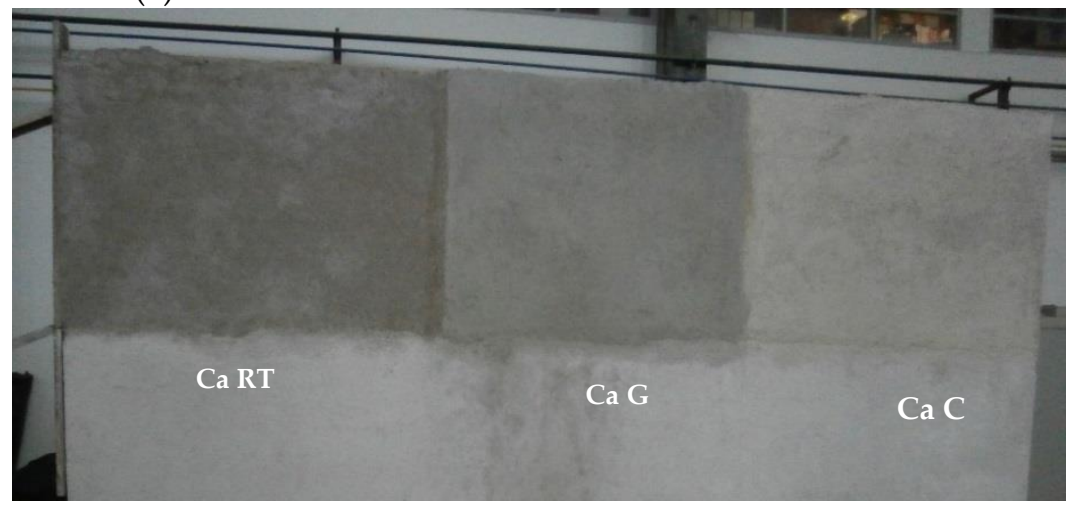

(c)

Figure 2. Test panels: (a) large scale model; (b) application of the mortars on testing panels; (c) final appearance of the mortars after the application.

\subsection{Testing procedure}

In order to study the effect of ageing on the properties and durability of air lime mortars, artificial ageing tests, comprising rain/heat and freeze/thaw cycles, were performed. Artificial ageing tests were designed on the basis of climatic conditions in Portugal (average air temperature climate records [7]) and were composed by the following cycles:

- $\quad 24 \mathrm{~h}$ rain/heat cycle $(\mathrm{RH})$ replicated 10 times: heating at $40{ }^{\circ} \mathrm{C}$ for $4 \mathrm{~h}$, followed by a rain period, for $4 \mathrm{~h}$, with an intensity of $1 \mathrm{l} / \mathrm{min}$ at $20^{\circ} \mathrm{C}$ and a drying period of $16 \mathrm{~h}$ at $20^{\circ} \mathrm{C}$;

- $\quad 12 \mathrm{~h}$ freeze/thaw cycle (FT) replicated 10 times: rain period, for $4 \mathrm{~h}$, with an intensity of $1 \mathrm{l} / \mathrm{min}$ at $20^{\circ} \mathrm{C}$ followed by a freeze at $-10^{\circ} \mathrm{C}$ for $4 \mathrm{~h}$, and a drying period of $4 \mathrm{~h}$ at $20^{\circ} \mathrm{C}$.

The cycles were performed with a climatic chamber (Aralab FITOTERM 10000 ELC) about three months after application, in order to ensure a good carbonation and an improvement of the properties of the lime mortars.

The behaviour of the mortars has been assessed by using the techniques described below; tests and analyses were performed before and after cycles.

To compare the obtained results, the specimens were also tested under laboratory conditions.

\subsubsection{Large scale model characterization} cluded:

The large scale model tests performed to evaluate the performance of the applied renders in-

- $\quad$ Evaluation of the mechanical strength and deformability, using a Schmidt hammer (Figure 3a);

- Evaluation of the surface hardness, and indirectly, the cohesion, using a Shore A durometer

(Figure 3b); 
- Adhesion to background (Figure 3c);

- Evaluation of compactness and stiffness of the renders, and detection of possible damaged zones using ultrasonic pulse velocity (Figure 3d);

- Moisture content on the mortars' surface.

These tests have been presented in previous works $[1,8]$.

Infrared thermography was also used to identify anomalies, mainly detachments, and evaluate the drying phase after the RH cycle (Figure 3e). This non-destructive and non-contact testing method consists on measuring the thermal radiation that comes from a surface and transforming it into electrical signals equivalent to temperatures that are displayed in the form of a thermal image (thermogram), in which different colours correspond to different temperatures, according to a defined scale [9].

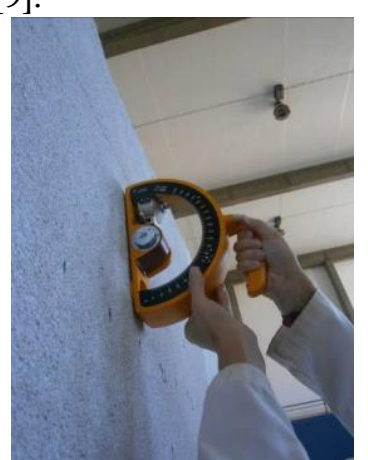

(a)

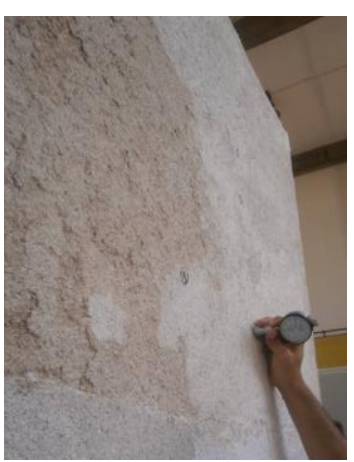

(b)

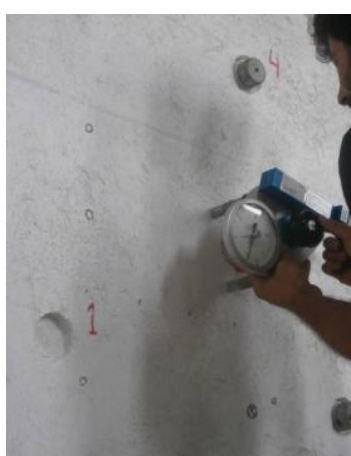

(c)

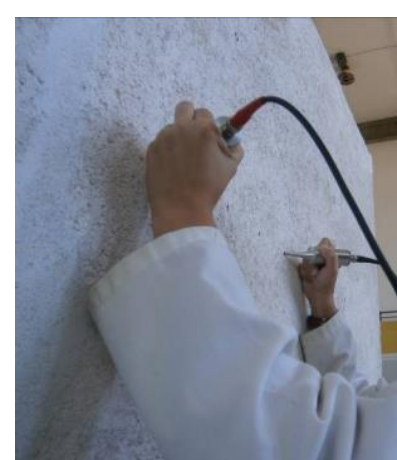

(d)

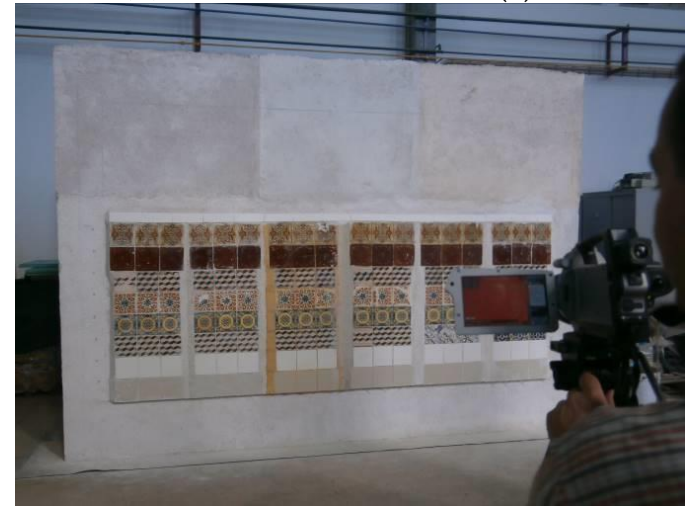

(e)

Figure 3. Tests on the panels: (a) Schmidt hammer; (b) Shore hardness; (c) Pull-off; (d) Ultrasound and (e) Infrared thermography.

\subsubsection{Laboratory characterization}

A laboratory characterization of the mixes used in the first coat of each panel was performed. Physical and mechanical characteristics and water performance (water absorption and drying curves, capillarity coefficient) were evaluated, for comparison with the values obtained in panels. The tests were carried out following European Standards [10-13].

\section{Results and discussion}

\subsection{Laboratory speciemens characterization}

The results of laboratory tests at 90 days are summarized in Table 2 and Figure 4.

Table 2. Results of tests on the hardened mortars at 90 days.

\begin{tabular}{lccccccc}
\hline Acronym's & $\begin{array}{c}\text { Bulk } \\
\text { density }\end{array}$ & $\mathbf{P}_{0}$ & $\mathrm{E}$ & Rt & Rc & $\mathrm{CC}_{10-90}$ & $\mathrm{~S}$ \\
\hline
\end{tabular}




\begin{tabular}{cccccccc}
\hline & $\mathbf{k g} / \mathbf{m}^{3}$ & $\mathbf{\%}$ & $\mathbf{M P a}$ & $\mathbf{M P a}$ & $\mathbf{M P a}$ & $\mathbf{k g} / \mathbf{m}^{2} \cdot \mathbf{m i n}^{\mathbf{1} / 2}$ & \\
\hline Ca RT & 1720 & 25.8 & 2720 & 0.39 & 0.55 & 1.71 & 0.80 \\
Ca C & 1850 & 25.6 & 3270 & 0.52 & 1.26 & 1.68 & 0.90 \\
Ca G & 1860 & 26.3 & 3600 & 0.61 & 1.14 & 1.84 & 0.93 \\
\hline
\end{tabular}

Po - Open porosity; E - Dynamic modulus of elasticity; Rt - Flexural strength; Rc - Compressive strength; CC 10 90 - Capillary water absorption coefficient between the 10 and 90 minutes; $\mathrm{S}$ - Saturation coefficient.

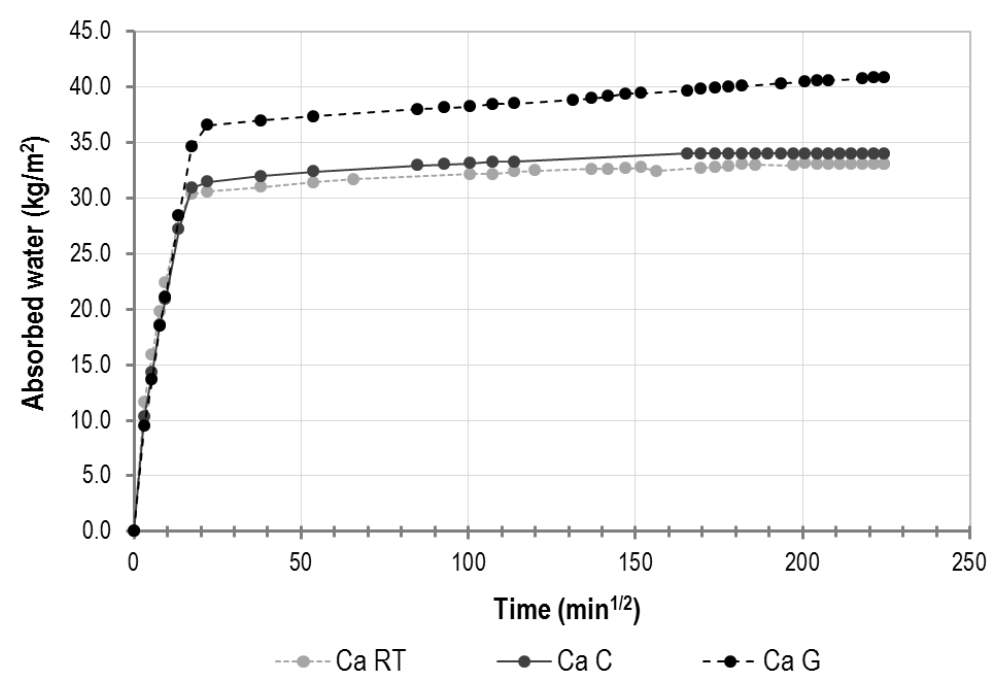

(a)

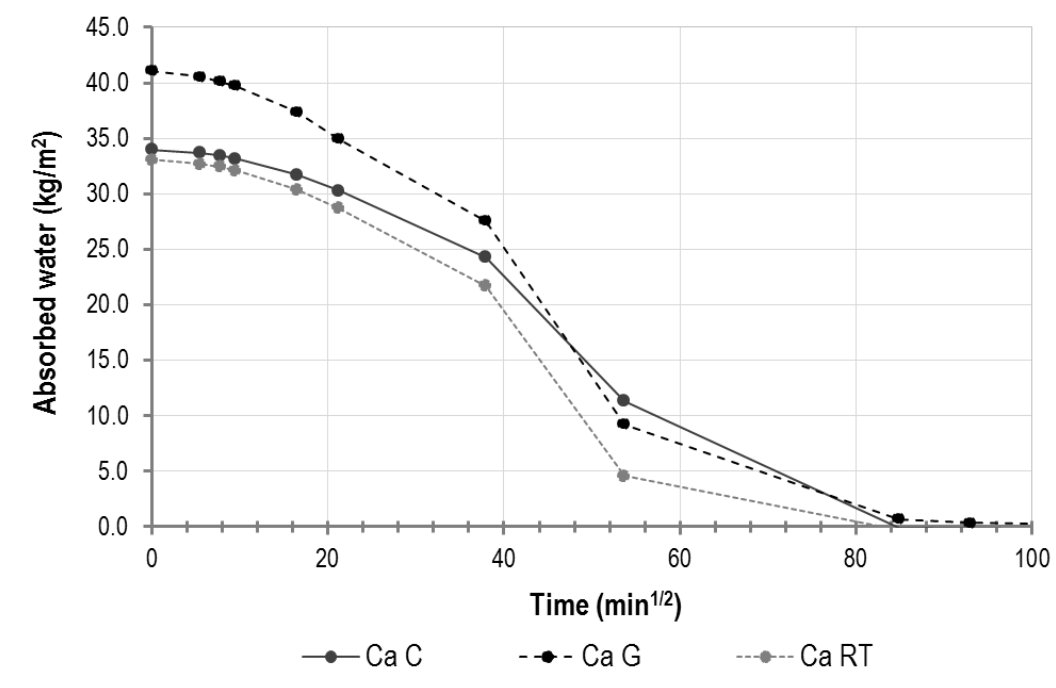

(b)

Figure 4. Water performance of the studied mortars at 90 days: (a) capillary water absorption curves; (b) drying curves.

From the physical properties of laboratory mortars (Table 2 and Figure 4), the highest total absorption and capillary water absorption coefficient were observed in the Ca G mortar, which also showed moderate drying capacity. On the other hand, mortars with calcareous or siliceous sand show similar behaviour concerning water absorption. However, the $\mathrm{Ca} \mathrm{C}$ mortar presented lower drying capacity, with lower porosity and consequently lower permeability than the other mortars, which can be a negative parameter on the assessment of the durability of this mortar.

Furthermore, the mortar with siliceous sand (Ca RT) had the lowest saturation coefficient and larger number of unfilled voids, resulting in a high resistance to damage resulting from the frost action [14, 15]. 
Mortars prepared with limestone sand had the highest values of compressive (Rc) strength, at 90 days, which can be attributed to the syntaxial growth of calcite particles over the lime calcareous stone grains and the crystallographic continuity between limestone aggregates and the lime matrix [16]. However, the flexural strength (Rt) as the dynamic elastic modulus (E) presented higher values in the mortars prepared with granitic sand. This contradictory behaviour of the $\mathrm{Ca} C$ can be probably attributed to the significant presence of a filler fraction, that can promote shrinkage and consequently micro-cracking on the interface aggregate/binder, to which the flexural strength is very sensitive.

\subsection{Mortars applied on large-scale model characterization}

\subsubsection{Mechanical characterization}

The analyses of the applied mortars on large-scale model are synthesised in Table 3.

Table 3. Results of tests on the mortars applied in large scale model before and after ageing cycles.

\begin{tabular}{|c|c|c|c|c|c|c|c|c|c|c|}
\hline \multirow{3}{*}{ Acronym's } & \multirow{2}{*}{\multicolumn{2}{|c|}{$\begin{array}{l}\text { Schmidt ham- } \\
\text { mer }\left(\mathrm{VH}^{+}\right)\end{array}$}} & \multirow{2}{*}{\multicolumn{2}{|c|}{$\begin{array}{c}\text { A Shore } \\
\text { hardness }^{++}\end{array}$}} & \multirow{2}{*}{\multicolumn{2}{|c|}{ Adhesion (MPa) }} & \multicolumn{4}{|c|}{ Ultrasound pulse velocity test } \\
\hline & & & & & & & & & & \\
\hline & BC & $\mathrm{AC}$ & BC & AC & BC & AC & BC & AC & BC & AC \\
\hline Ca RT & 24 & 22 & 65 & 65 & $\begin{array}{c}0.03- \\
\mathrm{B}^{*}\end{array}$ & $0.10-B^{*}$ & 750 & 690 & 880 & 750 \\
\hline $\mathrm{CaC}$ & 19 & 20 & 85 & 88 & $\begin{array}{c}0.06- \\
\mathrm{B}^{*}\end{array}$ & $0.05-B^{*}$ & 850 & 740 & 1220 & 920 \\
\hline Ca G & 32 & 31 & 85 & 88 & $\begin{array}{c}0.06- \\
\mathrm{B}^{*}\end{array}$ & $0.13-B^{*}$ & 830 & 920 & 1140 & 1410 \\
\hline
\end{tabular}

BC - Before cycles; AC - After cycles RH and FT; Vp - longitudinal waves velocity; E - Elastic modulus based on ultrasound pulse velocity; ${ }^{-}$- B: cohesive rupture in the render; ${ }^{+}$Vickers VH: $<20$ - very low; 20-30 - low; 30-40 moderate; ${ }^{++}$Unit measurement scale SHORE A from 0 to 100: 50-70 - moderate; 70-87 - normal; > 88 - very stiff.

Concerning the mechanical characteristics (Table 3), the Ca G panel shows the best performance, with good cohesion and adhesion to the substrate. After the cycles, the Ca G mortar seems to improve its performance with an increase of compactness, strength and adhesion to the substrate. These increments are probably due to the high open porosity that allows a better diffusion of $\mathrm{CO}_{2}$, which leads to a higher carbonation rate ( $86 \%$ compared to $84 \%$ of $\mathrm{Ca} \mathrm{C})$, but also reduces the stress caused by the increase of volume, due to ice formation during the FT cycles.

The Ca RT mortar shows low compactness and strength, probably caused by bad cohesion between matrix and aggregate grains.

On the other hand, $\mathrm{Ca} C$ has the lowest value of Schmidt hammer measurement and relatively low values of ultrasound pulse velocity and modulus of elasticity; those values are in contrast with the high surface hardness and with the elastic modulus and mechanical strength determined in laboratory, and can be attributed to the loss of adherence to the substrate of this mortar.

The adhesion to the substrate is low for all the mortars, but can be considered acceptable, considering the limit values defined in a previous work [17], especially taking into account, the cohesive rupture pattern within the render and not an adhesive pattern between render and substrate.

\subsubsection{Infrared thermography characterization}

In order to analyse the possibility of detecting early damage of the mortars, before the anomaly turns visible, several measurement campaigns using infrared thermography were performed, before and after the ageing cycles.

Figures 5 to 7 show the thermograms taken in different phases of weathering cycles.

\section{Before rain/heat cycles (RH):}

- After heating at $40{ }^{\circ} \mathrm{C}$, during 5 hours 


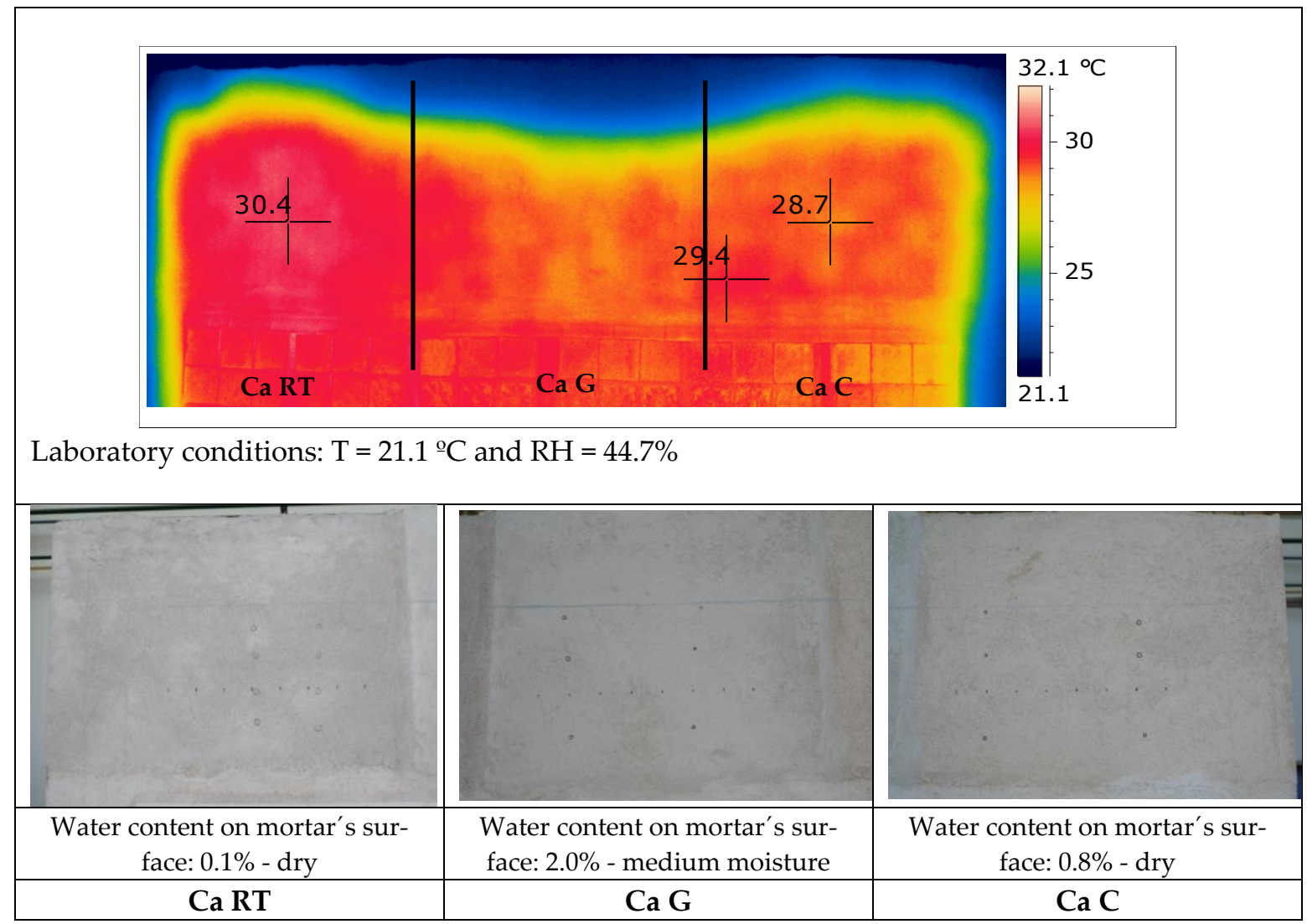

Figure 5.Thermograms and general aspect of the panels before cycles.

Before the cycles, all test panels show a good behaviour without cracks or any visible damage. The use of infrared thermography (Figure 5), before the cycles, allowed identifying few heterogeneities in terms of surface temperature of the mortars panels:

- Panel Ca RT registered the highest surface temperature, attributed to the non-uniformity of heat flow in all panels.

- Panel Ca C showed a zone (lower left) with higher superficial temperature than the remaining panel $\left(29.4^{\circ} \mathrm{C}\right.$ to $\left.28.7^{\circ} \mathrm{C}\right)$, probably due to the lack of adhesion to the substrate or between the layers; in fact, the thin air layer introduced by the detached render creates an additional thermal resistance, which causes higher surface temperature when heated.

2. After rain/heat cycles (RH):

- Immediately after the end of the RH cycles

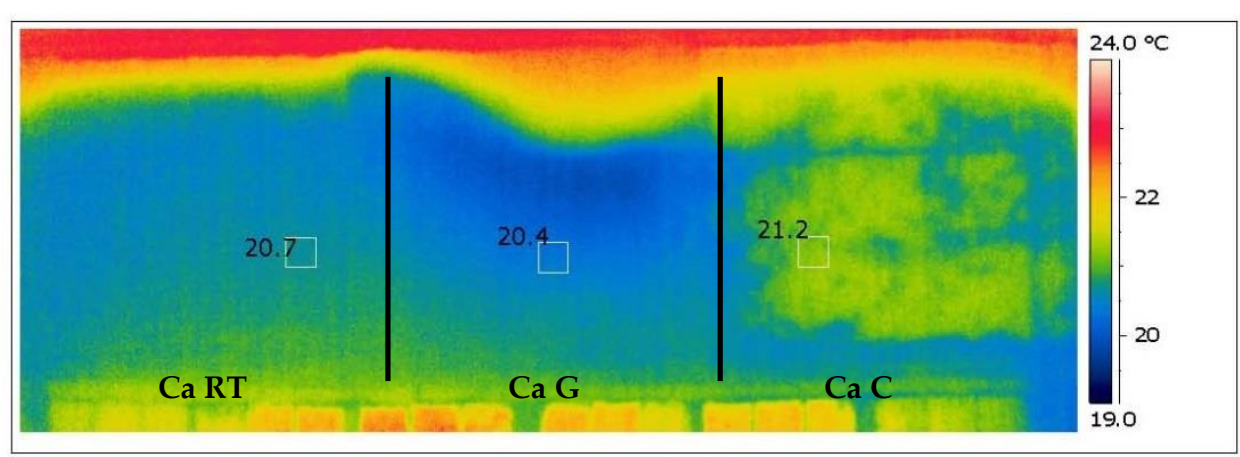

(a)

Laboratory conditions: $\mathrm{T}=22.4^{\circ} \mathrm{C}$ and $\mathrm{RH}=62.1 \%$ 


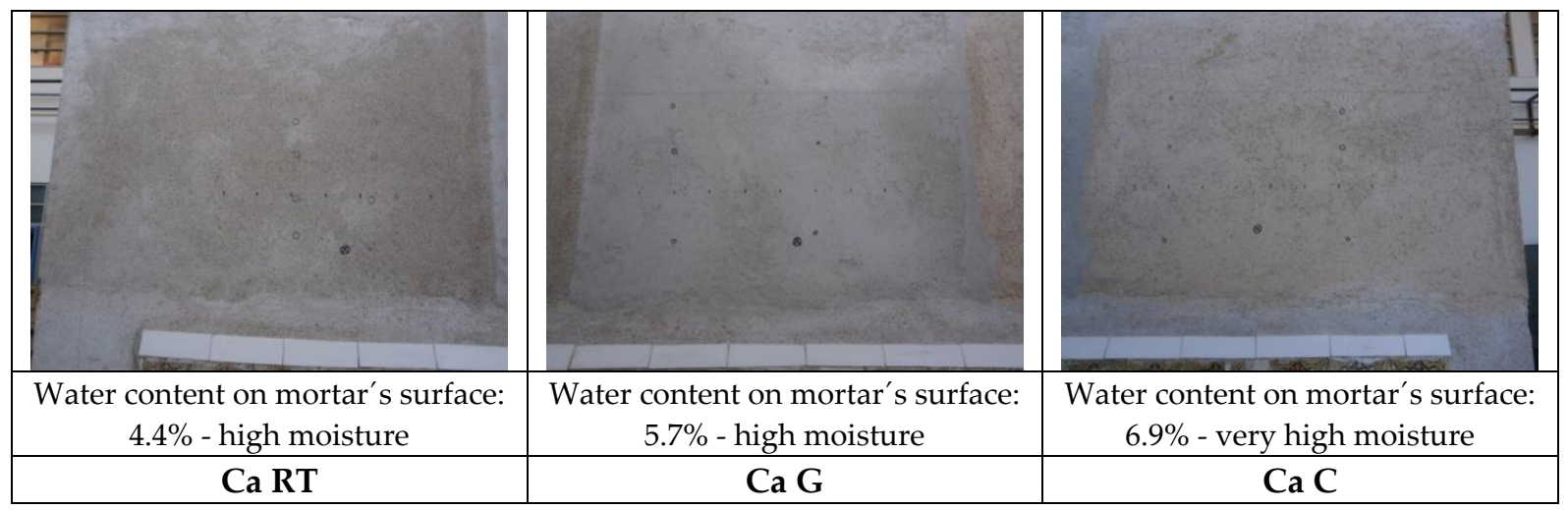

- After natural drying

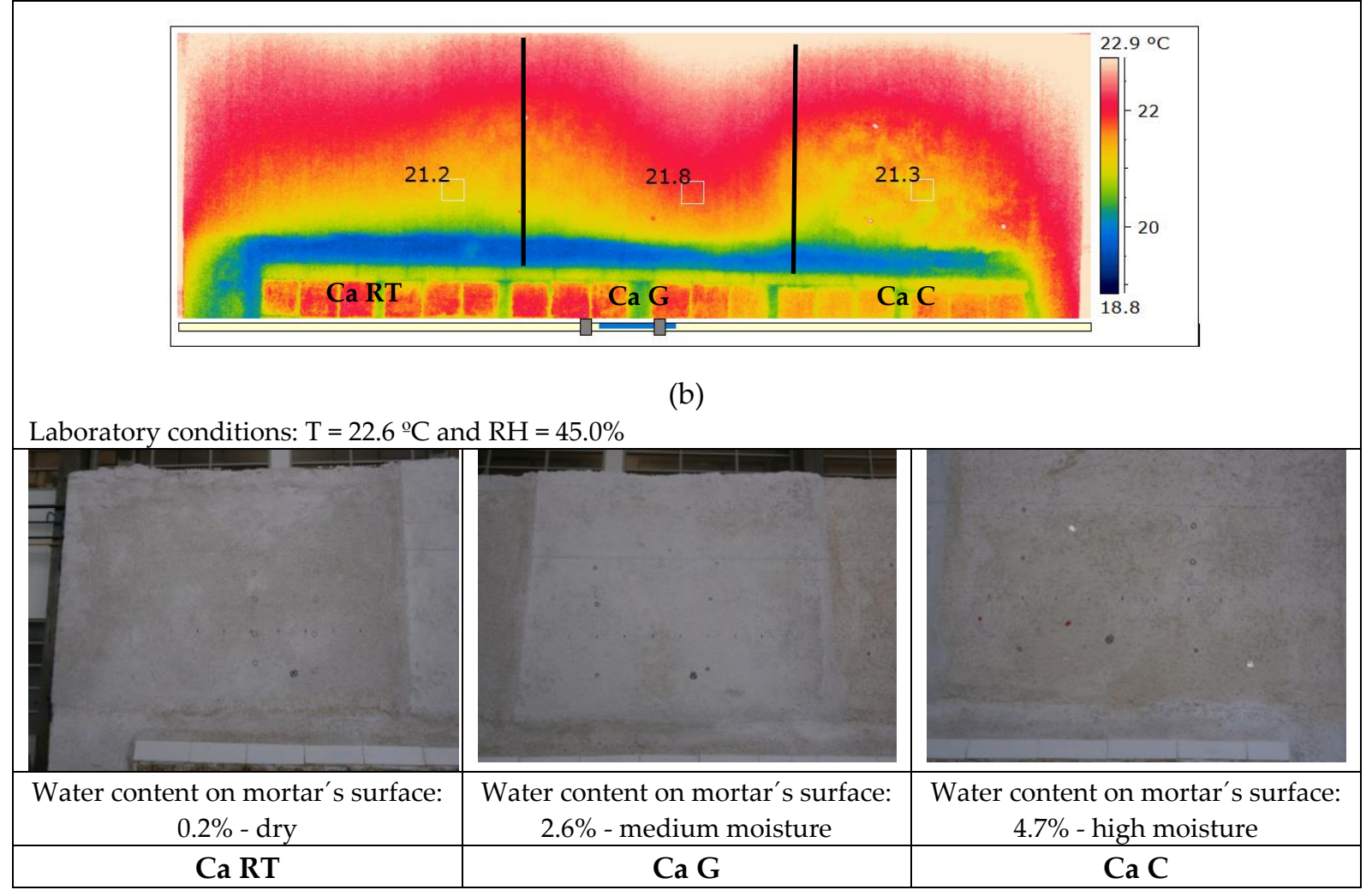

Figure 6. Thermograms and general aspect of the panels: (a) after RH cycles;

(b) after natural drying.

After the RH cycles all panels showed good appearance, without cracks or disaggregation.

Immediately after RH cycles, infrared thermographic observations were also made (Figure 6a):

- Few heterogeneities in terms of surface temperature of the mortar panels were observed, with a maximum temperature difference near $1^{\circ} \mathrm{C}$;

- $\quad$ The highest surface temperature was registered in Ca C mortar $\left(21.2^{\circ} \mathrm{C}\right)$, with heterogeneities on this panel and higher superficial water content $(6.9 \%)$ This contradictory behaviour (higher superficial temperature and also higher water content on mortar's surface) is probably due to the highest emissivity and roughness of the limestone panel and also influenced by its low surface evaporation;

- The different moisture ratios probably are linked to the total absorption and different drying rate of the mortars and to a possible lack of adhesion in Ca $\mathrm{C}$, which increase the superficial water content of this mortar.

During the model's natural drying (Figure 6b), the differences registered in the superficial temperature are according to the drying rate of the analysed laboratory mortars. The granite mortar presents the lowest surface temperature in the first days and the highest temperature at the end of the 
drying phase $\left(20.4^{\circ} \mathrm{C}\right.$ to $\left.21.8^{\circ} \mathrm{C}\right)$; in fact, this mortar shows the highest value of open porosity, water absorption and drying rate.

3. After freeze/thaw cycles (FT):

- After heating of $40^{\circ} \mathrm{C}$, during 5 hours

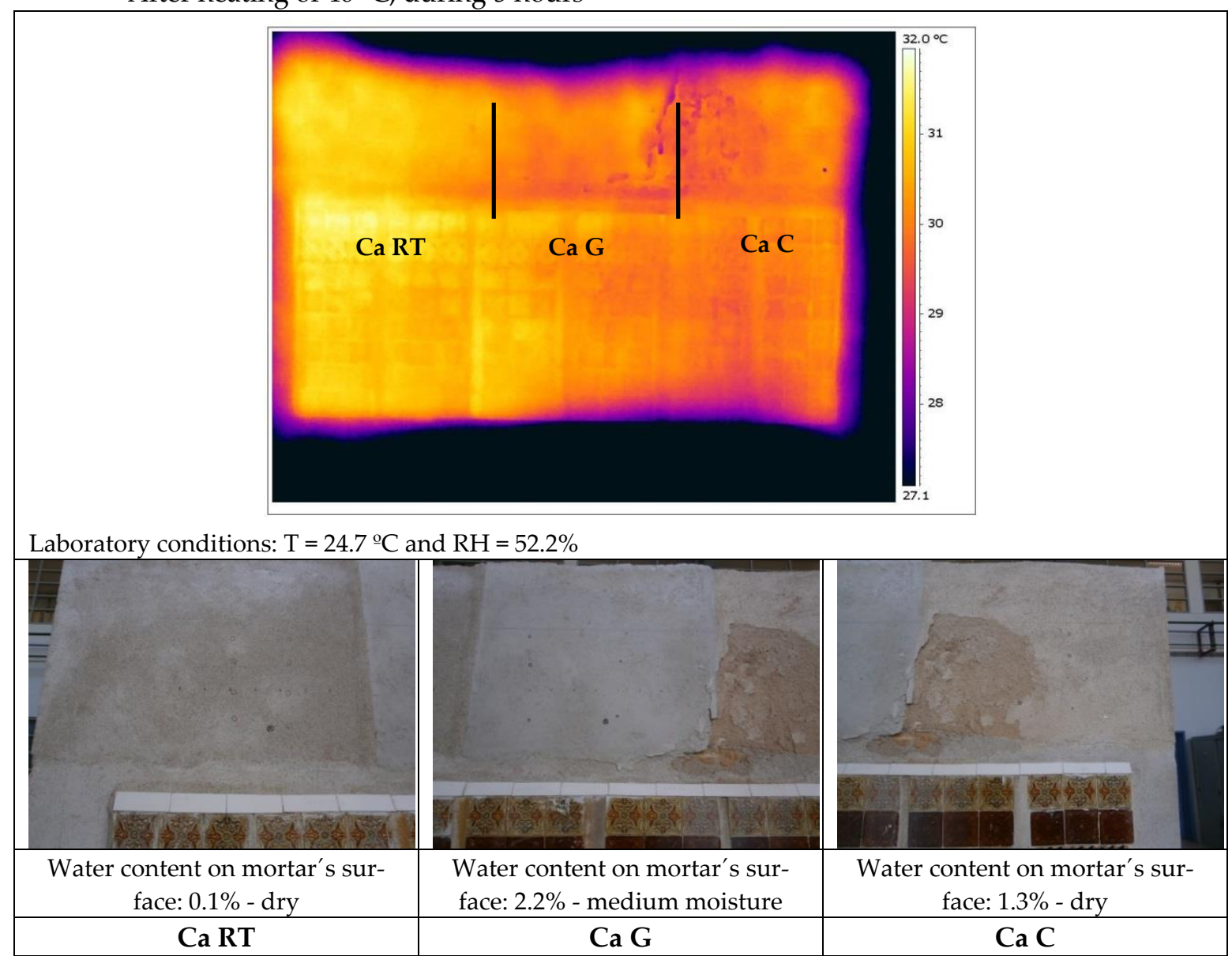

Figure 7. Thermograms and general aspect of the panels after FT cycles.

FT cycles were the most aggressive to mortars, namely to Ca C, causing the detachment of part of the mortar (Figure 7). The deterioration observed in this mortar may be due to its porous structure. In fact, the laboratory characterization showed that Ca C, when compared with the other studied mortars, presented the lowest open porosity and drying rate and highest coefficient of saturation (Table 2 and Figure 4).

Besides these characteristics of Ca C mortars, the infrared thermography, before the cycles, already indicated a possible lack of adhesion to the substrate or between the layers in the area where the detachment took place. The detachment area is contiguous to the Ca G panel, possibly leading to a fragile zone during the cycles that allows the water to get in between the render layers and freeze inside, increasing its volume and causing the deterioration of the mortar surface.

Ca RT and Ca G panels showed good appearance, without cracks or disaggregation after freeze/than cycles.

\section{Conclusions}

The influence of the aggregate characteristics on the durability performance of the lime mortars, which were applied on a large scale-model and subjected to ageing cycles, were studied.

Generally, air lime mortars showed a good behaviour in the artificial ageing tests. All mortars resisted without visible damage to the rain/heat cycles and the failure that occurred in the Ca C mor- 
tar during the freeze/thaw cycles may be mostly due to its porous structure. These events demonstrate how important the choice of a correct methodology is to determine the durability of construction materials. Also, the curing conditions and the application techniques play a fundamental role in the final characteristics of lime renders.

Concerning the mechanical behaviour and durability performance of the mortars, both seem to be linked to the porous structure. The use of different grain size distribution of the sands and aggregates with different characteristics (shape and mineralogy) has the capacity of modifying the porous network system [18] and consequently the weathering resistance.

The use of well graded aggregate leads, in general, to a reduction of the macropores forming smaller pores, which enhances the mechanical strength and consequently the weathering resistance. However, a compact pore network, under certain conditions, can cause an increase of the stresses due to the ice formation or salts crystallization, making them more vulnerable to the action of these mechanisms.

Mortar with granitic sand (Ca G) seems to improve its performance, even after FT cycles, with an increase of compactness, strength and adhesion to the substrate. This behaviour is probably due to its well graded sand that will enhance the mechanical strength and consequently the weathering resistance. Furthermore, aggregates that are source of silica, like G, can react with lime, in the presence of water during the test, leading to the formation of reaction rims at the edge of the grains and recrystallization along the pre-existing cracks, which may also increase the weathering resistance.

The good interconnectivity of the pore channels (high open porosity) of the Ca G mortar, allows a better diffusion of $\mathrm{CO}_{2}$, which leads to a higher carbonation rate and faster drying, enhanced by the presence of large pores, which also reduce the stress caused by the increase of volume due to ice formation during the Freeze-Thaw cycles.

The use of sub-rounded shape aggregates in Ca RT mortar also leads to an increase of large capillary pores and "air voids", which allows the pressure of freezing water to be released into these pores without damaging the mortar.

On the other hand mortars with limestone aggregates (Ca C), with similar mechanical strength characteristics in laboratory tests, reduce their performance after FT cycles, with a decrease of compactness, and adhesion to the substrate, probably due to partial destruction of pore system caused by the freeze/thaw mechanism. In fact, lime mortars with limestone sand, due to their mineralogy have a high coefficient of saturation but also a very compact porous structure and low permeability, due to the best adherence of limestone aggregates to the lime matrix and also probably due to a lower $\mathrm{w} / \mathrm{b}$ ratio, that does not allow the fast evaporation of capillary or absorbed water, making the render more vulnerable to damage. Therefore, the use of limestone in air lime mortars and the presence of water in their porous network may promote significant damage if temperature decreases until negative values.

In order to achieve the greatest possible frost-resistance of the renders, the recommendations are to use sands with continuous gradation of particles of all sizes; choose mortars with a low/medium coefficient of saturation and with good drying behaviour.

Author Contributions: All authors make substantial contributions for this work reported.

Funding: This research was funded by National Laboratory for Civil Engineering within the scope of Research Project "PRESERVe", by CERIS-IST and by Portuguese Foundation for Science and Technology (FCT) through the PTDC/EPH-PAT/4684/2014 project: DB-Heritage - Heritage database on historical construction materials. The testing materials were supplied by Lena Agregados S.A. and Lusical S.A.

Acknowledgments: The authors thank LNEC technicians Bento Sabala and Ricardo Resende for their collaboration in carrying out the tests. Also the collaboration of Sandro Botas on the mortars application.

Conflicts of Interest: The authors declare no conflict of interest.

References

1. Veiga, M., Santos, A. R., Santos, D. Natural Hydraulic Lime Mortars for rehabilitation of old buildings: Compatibility and Performance. Proceedings of 2015 Conference and Gathering of the Building Limes Forum, Cambridge, September 2015. 
2. Vilhena, A., Matias, L., Cristian, A., Santos, C., Veiga, M. Laboratory thermographic analysis of masonry specimens. Capillarity and drying. Proc. 7th International Symposium on the Conservation of Monuments in the Mediterranean Basin. Water and Cultural Heritage, Orléans, June 2007.

3. Arizzi, A., Viles, H., Cultrone, G. Experimental testing of the durability of lime based mortars used for rendering historic buildings. Construction and Building Materials, 28 (2012).

4. Lanas, J., Sirera, R., Alvarez, J.I. Study of the mechanical behaviour of masonry repair lime-based mortars cured and exposed under different conditions. Cement and Concrete Research, 36 (2006).

5. Instituto Português da Qualidade (IPQ) - NP EN 459-1:2015, Building lime; Part 1: Definitions, specifications and conformity criteria.

6. European Committee for Standardization (CEN) - EN 1015-3:1999, Methods of test for mortar for masonry; Part 3: Determination of consistence of fresh mortar (by flow table).

7. IPMA Climate records https://www.ipma.pt/en/oclima/extremos.clima/ (25/10/2017).

8. Veiga, M., Velosa, A., Magalhães, A. Experimental applications of mortar s with pozzolanic additions: Characterization and performance evaluation. Construction and Building Materials, 23 (2009).

9. Lourenço, T.; Matias, L., Faria P. Anomalies detection in adhesive wall tiling systems by infrared thermography. Construction and Building Materials, 148 (2017).

10. Instituto Português da Qualidade (IPQ) - NP EN 1936:2008, Natural stone test methods; Determination of real density and apparent density, and of total and open porosity.

11. European Committee for Standardization (CEN) - EN 1015-11:1999, Methods of test for mortar for masonry Part 11: Determination of flexural and compressive strength of hardened mortar.

12. Instituto Português da Qualidade (IPQ) - NP EN 14146:2006, Natural stone test methods; Determination of the dynamic modulus of elasticity (by measuring the fundamental resonance frequency).

13. European Committee for Standardization (CEN) - EN 1015-18:2002, Methods of test for mortar for masonry; Part 18: Determination of water absorption coefficient due to capillary action of hardened mortar.

14. Pavía, S.; Treacy, E. A comparative study of the durability and behaviour of fat lime and feebly-hydraulic lime mortars. Materials and Structures, 39 (2006).

15. RILEM TC 25-PEM Recommended tests to measure the deterioration of stone and to assess the effectiveness of treatment methods. Part II - Tests defining the properties connected with the presence and the movement of water. Test II. 1 - Saturation Coefficient. Materials and Structures, 13 (1980).

16. Cultrone, G.; Sebastian, E.; Ortega Huertas, M. Durability of masonry systems: A laboratory study. Construction and Building Materials, 21 (2007).

17. Veiga, M., Santos, A. R., Marques, A., Santos, D. Non Standard testing of mechanical characterization to support the conservation of old renderings. Proc. PROHITECH'17 - $3^{\text {rd }}$ International Conference on Protection of Historical Constructions, Lisboa, July 2017.

18. Santos, A.R.; Veiga, M.R.; Santos Silva, A.; de Brito, J.; Alvarez, J.I. Evolution of the microstructure of lime based mortars and influence on the mechanical behaviour: The role of the aggregates. Construction and Building Materials, 187 (2018). 